\title{
LA RESPONSABILIDAD SOCIAL CORPORATIVA COMO OPORTUNIDAD PARA LAS EMPRESAS TURÍSTICAS
}

\author{
Alfonso Gomis Rodríguez \\ Antón Álvarez Sousa \\ Gustavo Rego Veiga \\ José Leira López \\ Rosa Caramés Valo \\ María José Andrade Suárez ${ }^{1}$ \\ Universidade da Coruña
}

\begin{abstract}
Resumen: Primero se hace una aproximación general a la responsabilidad social empresarial y se comentan algunas características de este nuevo modelo de gestión. Después se hace un repaso de algunas de las responsabilidades que cabe esperar que desarrollen las empresas turísticas, así como algunas iniciativas, dentro y fuera del sector del turismo, para fomentar la responsabilidad por parte de distintos organismos internacionales, y las iniciativas desarrolladas por las propias empresas. En los últimos apartados se estudia una iniciativa concreta, la norma SA8000 de auditoría social, y las memorias de sostenibilidad.
\end{abstract}

Palabras clave: Responsabilidad social empresarial (RSE), turismo sostenible, memorias de sostenibilidad, norma SA8000, guías GRI.

Resumo: $A$ responsabilidade social corporativa como oportunidade para as empresas turísticas. En primeiro lugar realízase unha aproximación xeral ao concepto de responsabilidade social empresarial e coméntanse algunhas das características deste novo modelo de xestión. A seguir, repásanse algunhas das responsabilidades que cabe esperar que as empresas turísticas asuman, así como tamén algunhas iniciativas de dentro e fóra do sector do turismo para fomentar a RSC por parte de distintos organismos internacionais, e as iniciativas desenvolvidas polas propias empresas neste sentido. Nas últimas seccións estúdase unha iniciativa concreta, a norma SA8000 de auditoría social, e as memorias de sustentabilidade.

Palabras clave: responsabilidade social empresarial (RSE), turismo sustentable, memorias de sustentabilidade, norma SA8000, guías GRI.

Abstract: Corporate Social Responsibility as an opportunity for tourism companies.

1 Alfonso Gomis Rodríguez: agomis@udc.es, Antón Álvarez Sousa: sousa@udc.es, Gustavo Rego Veiga: gusrego@udc.es; José Leira López: leira@udc.es, Rosa Caramés Valo: carames@udc.es, María José Andrade Suárez:mandrade@udc.es 
This study begins with a general overview of corporate social responsibility, commenting on some of the characteristics of this new management model. The study then reviews some of the responsibilities that tourism companies can be expected to perform, as well as some initiatives, both inside and outside the tourism sector, to promote responsibility by different international bodies, and the initiatives performed by the companies themselves. The final sections study a specific initiative, standard SA8000 on social accountability, and sustainability reports.

Key words: Corporate social responsibility (CSR), sustainable tourism, sustainability reports, standard SA8000, GRI guidelines.

\section{INTRODUCCIÓN}

En las tres últimas décadas las políticas de privatización y desregulación han puesto de manifiesto una crisis de responsabilidad, mostrando una situación de desequilibrio económico, social y ambiental. Hemos visto como el poder real se ha ido desplazando, cada vez más, hacia las empresas, superando -e incluso condicionando- al poder político y debilitando el poder de los sindicatos. Para muchos parece lógico que sean las empresas las que inicien actuaciones a fin de mejorar algunos de los desequilibrios medioambientales y sociales hoy existentes. Al mismo tiempo, la necesidad de un mayor control sobre las empresas y de que éstas informen a los afectados por sus actividades, han favorecido la aparición de la Responsabilidad Social Corporativa (RSC) o Empresarial $(\mathrm{RSE})^{2}$. La propia denominación parece poner de manifiesto que hasta ahora se había actuado de forma irresponsable.

La RSE es la contribución empresarial al desarrollo sostenible, y puede ser definida (así lo hacía la Comisión Europea en 2001) como "la integración voluntaria, por parte de las empresas, de las preocupaciones sociales y medioambientales en sus operaciones comerciales y sus relaciones con sus interlocutores. Ser socialmente responsable no significa solamente cumplir plenamente las obligaciones jurídicas, sino también ir más allá de su cumplimiento invirtiendo «más» en el capital humano, el entorno y las relaciones con los interlocutores". La experiencia adquirida con la inversión en tecnologías y prácticas comerciales respetuosas del medio ambiente sugiere que ir más allá del cumplimiento de la legislación puede aumentar la competitividad de las empresas. La aplicación de normas más estrictas que los requisitos de la legislación del ámbito social, por ejemplo en materia de formación, condiciones laborales o relaciones entre la dirección y los trabajadores, puede tener también un impacto directo en la productividad. Abre una vía para administrar el cambio y conciliar el desarrollo social con el aumento de la competitividad (Comisión Europea, 2001).

2 En la década de 1970 hubo distintas iniciativas en el ámbito social de las empresas, como la Ley francesa sobre Balance Social de 1977, que obligaba a las empresas de más de 300 empleados a presentar anualmente datos acerca de su actuación en temas de índole social a través de una serie de indicadores sociales. En los 80 esto pasó a un segundo plano, porque se privilegió la maximización de beneficios y el enriquecimiento al más corto plazo posible. El interés resurgió en los años 90 de la mano de la "sostenibilidad". 
Con este nuevo enfoque, la empresa debe seguir funcionando como antes, con la responsabilidad principal de generar beneficios, pero además debe tener una actitud más consciente de su impacto sobre el medio ambiente y sobre las personas. Las empresas turísticas, además de prestar un servicio que responda a las necesidades de sus clientes, deben ir más allá del cumplimiento de las leyes, y preocuparse por el impacto de sus actividades en el entorno social y natural, aumentando el bienestar de sus empleados, proveedores y comunidad local en donde están asentadas.

Sabemos que el sector de los viajes y el turismo es en muchos lugares la principal fuente de ingresos y conocemos también muchas de las posibilidades que este sector ofrece. Ya en la Cumbre de Río de 1992 se identificaba a este sector como una de las pocas industrias que poseían el potencial de realizar una contribución positiva a la sostenibilidad de la vida en el planeta. Sin embargo, también son conocidas las muchas consecuencias negativas que el turismo puede ocasionar, desde daños al medio ambiente, malas condiciones de trabajo, con empleos precarios o falta de derechos sindicales, pérdida de valores culturales tradicionales, o situaciones de prostitución de mujeres e incluso de niños.

En este artículo pretendemos hacer una aproximación general a distintos aspectos de la RSE y mostrarla como una oportunidad que pueden aprovechar las empresas turísticas, en la medida en que -como señalan estudios realizados en distintos países- los cambios sociales y los nuevos modelos de consumo demandan nuevos productos y servicios turísticos basados en criterios de sostenibilidad y responsabilidad social, lo que ofrece un potencial considerable para este sector. Especialmente en los países menos desarrollados (a donde han dirigido sus inversiones muchas de las grandes empresas turísticas), el turismo basado en criterios de responsabilidad social puede contribuir a crear riqueza, generando beneficios a las empresas y a las poblaciones de los destinos. Es importante informar y sensibilizar a los clientes respecto a la RSE, al tiempo que la industria turística debe ofrecer transparencia y claridad en cuanto al trasfondo social de sus ofertas. De esta manera, los clientes pueden tomar decisiones responsables sobre sus viajes y fomentar el crecimiento del mercado del turismo responsable ${ }^{3}$.

El proceso para el desarrollo de la RSE consiste en identificar a los grupos de interés y conocer sus expectativas legítimas, diseñar las políticas y planes de actuación para llevarlas a la práctica, la información de los aspectos relevantes a cada grupo de interés, y por último, la verificación de todo el proceso ${ }^{4}$. Comenzaremos comentando algunas características generales de la RSE.

\footnotetext{
3 En este artículo apenas haremos referencias a lo que se ha denominado "turismo justo", que es una forma de turismo que va más allá de lo que es la RSE. Se puede definir como cualquier modalidad o actividad turística donde participan activamente agentes y productores locales, con una distribución equitativa y transparente del valor añadido por la actividad (basada en las contribuciones reales que cada uno realiza al proceso, y no en otros aspectos como poder de negociación relativa o disponibilidad de capital), asumiendo los principios de sostenibilidad (prácticas sostenibles a nivel social, cultural y medioambiental), el respeto a los derechos humanos y laborales, y donde se fomenta la participación democrática de la población local y el aprendizaje mutuo entre esta población y los visitantes, apoyándose en la sensibilización en origen y la capacitación en destino: Palomo, S. (2006a).
}

4 Declaraciones de José Félix González, director de RSE de Iberdrola, recogidas en Ser responsable, 1 sep. 08. 


\section{ALGUNAS CARACTERÍSTICAS GENERALES DE LA RSE}

\section{a) Voluntariedad y autorregulación:}

Asumir políticas de RSE es algo voluntario. Supone que las empresas, de forma voluntaria, pasan a exigirse el cumplimiento de unos objetivos que van más allá de los requeridos legalmente. Algunos entienden la RSE como una estrategia defensiva de las grandes empresas frente a las demandas de diversos sectores de la sociedad civil, por temor al impacto negativo que algunas de sus actividades pueden tener en la reputación o imagen de marca de la empresa. También se puede ver como una estrategia de algunos empresarios o sectores para evitar cualquier tipo de regulación. Frente a la regulación de las administraciones públicas, los empresarios prefieren la autorregulación y deciden informar voluntariamente sobre sus resultados no financieros para evitar que se imponga una reglamentación. También los gobiernos pueden encontrar beneficioso que las empresas se autorregulen, evitando así intervenir en los negocios privados. La cuestión que a veces se plantea es que, al tratarse de actuaciones voluntarias, éstas pueden quedar reducidas a algo secundario, a actuaciones más cercanas a la propaganda o la filantropía que a cambios significativos. Frente a esta visión, otros señalan que aunque la RSE sea una opción voluntaria, no impuesta por las administraciones públicas, su desarrollo favorece una forma de control sobre la actuación empresarial, no tanto por esas administraciones como por los trabajadores de la propia empresa, sus clientes, suministradores o público en general.

La Unión Europea ha defendido que el desarrollo de prácticas de RSE se articule a través de "acciones voluntarias" de las empresas y no prevé llevar a cabo una regulación de estas prácticas. La Comisión Europea reconoce la necesidad de complementar la regulación tradicional con instrumentos de "responsabilidad compartida", en particular la autorregulación. En la Comunicación de la Comisión sobre "Orientaciones básicas para la sostenibilidad del turismo europeo" (2003), se indicaba que la sostenibilidad del turismo requiere medidas políticas a todos los niveles, desde el global hasta el local, que aborden los modelos de consumo y de producción de la oferta del turismo, pero también se señalaba que las partes implicadas en el turismo (empresas, trabajadores, destinos, administraciones) eran las principales responsables de definir los marcos políticos del turismo y las medidas de aplicación. En esas orientaciones se defendía la autorregulación y la RSE (la Comisión señalaba que "no privilegia la idea de introducir instrumentos reguladores a pesar del escaso éxito registrado hasta la fecha por los instrumentos voluntarios desarrollados para el turismo sostenible" $)^{5}$. En todo caso, en los últimos

5 La Comisión reconocía que "a pesar de las numerosas iniciativas existentes, los modelos insostenibles de consumo y producción del turismo europeo aún no han sufrido ningún cambio considerable. Tanto los enfoques, iniciativas, instrumentos y buenas prácticas relacionados con la sostenibilidad en general, como la producción de la oferta turística y el desarrollo de los destinos turísticos, que pueden encontrarse en cualquier lugar, se han abordado sobre el terreno de forma insuficiente. En cuanto al consumo, la actividad turística europea no se está adaptando de forma básica a los requisitos de sostenibilidad en lo que respecta al transporte de turistas y a la elevada estacionalidad del turismo y sus repercusiones insostenibles en términos económicos, 
meses hemos visto que algunos países (como Noruega, Dinamarca o Suecia) están imponiendo la obligatoriedad de que al menos algunas empresas presenten informes de $\mathrm{RSE}^{6}$.

\section{b) La transparencia y el papel de los "stakeholders":}

La responsabilidad social debe suponer la transparencia informativa de la empresa en los tres ámbitos de la sostenibilidad, ya no sólo en el económico y financiero, sino también en el social y en el medioambiental, haciendo públicos sus resultados, dando cuenta ("accountability") de sus actuaciones y de su relación y compromiso con sus grupos de interés. Los grupos de interés, los "stakeholders", son aquellos individuos o entidades a los que pueden afectar de manera significativa las actividades, productos y/o servicios de la organización; y cuyas acciones pueden afectar dentro de lo razonable a la capacidad de la organización para desarrollar con éxito sus estrategias y alcanzar sus objetivos. Los límites de la responsabilidad de la empresa son muy difusos, y los grupos de interés son cada vez más numerosos. Según el grado de proximidad a la empresa, se podría distinguir entre:

- los grupos de interés primarios, que son aquellos que afectan o pueden ser afectados directamente con la actuación de la empresa: los empleados, accionistas, clientes, proveedores, comunidades locales;

- los grupos de interés secundarios, aquellos que no se relacionan directamente con la empresa, pero que pueden tener una influencia importante sobre la misma: grupos de presión social, ONGs defensoras de los consumidores o del medio ambiente, sindicatos, grupos políticos, instituciones municipales, competidores, gobierno, reguladores...

La teoría de los stakeholders -desarrollada por Edward Freeman- considera que las empresas no sólo son responsables ante los propietarios del capital o accionistas (shareholders), ni ante sus clientes, sino que su responsabilidad se extiende al logro de los objetivos de todos los grupos de interés afectados por sus actividades. Las empresas tienen contraídos compromisos no sólo con sus accionistas (como se defendía en el modelo anterior, orientado hacia la maximización del valor de la empresa a corto plazo para el accionista y del beneficio para el propietario), sino también con los restantes grupos de interés afectados por su actividad (y tanto mayores cuanto mayor y más directa sea la relación con ellos). Además, las empresas deben hacer suyos los valores sociales imperantes en su país de origen y aplicarlos en todos aquellos países en donde operen, aunque en ellos no estén vigentes los mismos valores, ni exista ley que las obligue. La participación y el intercambio de información con los posibles afectados tiene por objetivo conocer el impacto en ellos de las actividades de la empresa, conocer sus expectativas y

sociales y medioambientales. (Comisión de las Comunidades Europeas “Orientaciones básicas para la sostenibilidad del turismo europeo: Comunicación de la Comisión al Consejo, al Parlamento Europeo, al Comité Económico y Social y al Comité de las Regiones", Bruselas, 21.12.2003 COM (2003) 716 final).

6 Noruega acaba de aprobar su primer Libro Blanco de RSE que obliga a las empresas a informar anualmente de su comportamiento, en Dinamarca se ha aprobado que unas 1.100 grandes empresas incluyan en sus balances financieros anuales información sobre RSE y sus políticas de inversión responsable; y en Suecia se va a obligar a las empresas públicas a realizar informes de sostenibilidad a partir del 31 de marzo de este año. 
demandas, lo que permite a las empresas anticiparse a los riesgos a los que se enfrenta en sus actividades y que pudieran perjudicar su reputación, y crear nuevos productos y servicios capaces de satisfacer las nuevas necesidades sociales.

El Libro Verde de la Comisión Europea para fomentar un marco europeo para la RSE reconoce que para practicar la responsabilidad social de las empresas es esencial el compromiso de la alta dirección, una forma de pensar innovadora y una mayor participación del personal y sus representantes en un diálogo bidireccional que pueda estructurar una realimentación y un ajuste permanentes" ". En la adopción de prácticas socialmente responsables en el sector del turismo resultará fundamental el papel de los trabajadores, de los clientes/turistas y de la población local. En especial, el diálogo social con los representantes de los trabajadores, que incluye la negociación colectiva, sin duda la forma más importante de participación de los grupos de interés (Jiménez Fernández, 2007), y todo tipo de negociación, consulta o intercambio de información entre los representantes del gobierno, los empleadores y los trabajadores sobre temas de interés común relacionados con cuestiones económicas o sociales.

\section{c) Gestión basada en razones éticas y económicas:}

Ser responsable socialmente puede suponer para las empresas una cuestión estratégica de la que dependa su éxito o fracaso. Aunque los resultados no parecen suficientemente concluyentes, varios estudios afirman que hay una correlación positiva entre implantar políticas de responsabilidad social y el aumento de los beneficios para los accionistas, de modo que la RSE supone una ventaja competitiva para las empresas (Fuentes et al., 2006). Las compañías que se presentan más abiertas a los grupos de interés y que sitúan la responsabilidad social en el centro de su estrategia de negocio logran ser más competitivas, atraer y retener a los mejores talentos y ganar acceso a nuevas oportunidades de negocio ${ }^{8}$. Muchas empresas ven la RSE como una oportunidad de crecimiento y no sólo para el cumplimiento de normativas o como un esfuerzo filantrópico. Una empresa respetuosa con el medio ambiente y con la sociedad puede generar efectos positivos en sus resultados financieros. Mediante la articulación adecuada de las demandas de sus stakeholders, las empresas acaban maximizando sus resultados económicofinancieros y el valor creado para sus accionistas.

La razón para la responsabilidad social, por tanto, no sólo es ética, sino económica: la empresa debe atender adecuadamente a sus grupos de interés porque de todos ellos obtiene un recurso básico (tangible o intangible) para el óptimo desarrollo de su actividad: capital de los accionistas, ingresos de los clientes, suministros de los proveedores;

7 En todo caso, las empresas no deberán definir sus responsabilidades sociales o el contenido de sus informes sobre responsabilidad social sobre la base de las "partes interesadas" que determinen por su cuenta y elijan para que "participen". En algunos casos las partes interesadas más importantes son las que se evitan, o las empresas ayudan a crear, o proporcionan ayuda financiera, a las ONGs que están de acuerdo en hacer las veces de "partes interesadas".

8 Según un estudio presentado por IBM Institute for Business Value, citado en Ser responsable, 18 feb. 2008. Según ese estudio el 68\% de las empresas encuestadas encontraba en las actividades de RSE una fuente de ingresos, y el 54\% creía que las iniciativas de RSE contribuían a aportar a sus compañías una ventaja competitiva. 
fuerza de trabajo, talento, motivación e integración de los empleados; licencia para operar de los reguladores; buena valoración de los creadores de opinión; y aceptación y reputación de la sociedad. Recursos cuya consecución en las mejores condiciones para la empresa depende de la buena relación que consiga mantener con cada uno. Así, la ética en los negocios no es sólo una obligación moral, social o religiosa, sino que forma parte de la actividad y del beneficio empresarial. Especialmente en el caso de las multinacionales, ante la creciente competencia empresarial en todos los ámbitos de la economía y el poder de la información, estas empresas se ven abocadas por necesidad a empezar a cuidar aspectos clave de RSE.

En definitiva, la responsabilidad social ofrece muchas oportunidades a la empresa, como reforzar su imagen de marca, la fidelización de clientes, aumento de la confianza de accionistas e inversores y de la sociedad; motivación y cualificación de los recursos humanos, atracción y retención de talento, innovación, creación de valor para el accionista...

\section{d) La presión de los consumidores y de los inversores:}

En los últimos años asistimos al creciente interés de los ciudadanos (destacando, por su influencia, los consumidores y los inversores) por conocer la dimensión social y medioambiental de las actividades empresariales. Los consumidores están más concienciados sobre cuestiones como las prácticas laborales, seguridad de los alimentos, cambio climático o las aportaciones de las empresas al bienestar de la sociedad, y eso influye en sus decisiones de compra ${ }^{9}$. Algunos eligen un consumo responsable, buscando productos ecológicos o de acuerdo a criterios de RSE (comercio justo, bajo empleo de recursos no renovables, condiciones laborales justas...), o incluso boicotean a empresas que incumplen determinados criterios. La globalización ha llevado al crecimiento de las deslocalizaciones de empresas, muchas veces acompañadas de explotación de los trabajadores en las nuevas zonas donde se asientan. Algunos consumidores (bien directamente, bien a través de ONGs) no están dispuestos a consumir productos o servicios fabricados en situaciones abusivas. Ante determinadas noticias o situaciones, independientemente de lo que hagan las propias empresas, e incluso de que sean positivos los resultados económicos que obtengan, los activos intangibles de las empresas pueden desvalorizarse con rapidez. En el sector turístico, aunque hasta ahora no se han producido situaciones tan escandalosas como en otros sectores de la economía, también vemos el aumento de distintas formas de turismo responsable (llámense turismo justo, turismo comunitario, solidario o de otra forma) en un afán de oponerse a formas de turismo más problemáticas.

También la influencia de los inversores empuja a las empresas hacia la responsabilidad social. Los inversores están buscando formas de evaluar a las empresas en base a los factores intangibles que influyen en su rentabilidad. Contar con unos buenos resul-

9 Las encuestas a los consumidores realizadas por Fleishman Hillard en Estados Unidos en 2005, 2006 y 2007 han observado en cada edición que la responsabilidad y el compromiso de cara a los trabajadores son una de las preocupaciones más citadas por los consumidores en materia de RSE, más que la ética y la honradez (Fundación Entorno, 2008). 
tados de las empresas en cuestiones sociales y medioambientales empieza a tener un papel relevante en las decisiones de los agentes que intervienen en los mercados financieros, a la hora de decidir qué comprar. En los últimos años algunos escándalos económicos han alertado a los inversores sobre los parámetros no financieros a la hora de construir sus carteras de valores. Poco a poco, la percepción de que las normas acreditadas en materia de RSC son un buen indicador del futuro rendimiento económico-financiero de una determinada compañía gana adeptos. Vemos como en algunos países ha aumentado la Inversión Socialmente Responsable, es decir, fondos y empresas que desarrollan buenas prácticas de RSE. Como decíamos antes, algunos aprecian una correlación positiva entre rendimiento social y financiero, las empresas más responsables parecen ser, a la postre, las mejor gestionadas, de modo que la inversión en fondos socialmente responsables no parece implicar un impacto negativo en la rentabilidad. La existencia de índices de sostenibilidad, que integran a las empresas mejor valoradas desde el punto de vista de la sostenibilidad o de responsabilidad social, constituyen un atractivo adicional para que las compañías cotizadas formalicen sus políticas de RSE. Entre esos índices figuran el Dow Jones Sustainability Group Index y el FTSE4Good (y en España el FTSE4GoodIbex). Pretenden orientar a los inversores de mayor sensibilidad hacia el desarrollo sostenible y las prácticas sociales, y siguen determinados criterios, como compromiso con sus grupos de interés, prácticas laborales, desarrollo del capital humano, aprendizaje organizacional, informe social, atracción y conservación de trabajadores cualificados, estándares para proveedores, y criterios específicos para cada industria.

\section{TIPOS DE RESPONSABILIDADES}

M. Bestratén y L. Pujol (considerando sólo dos grupos de interés clave: los trabajadores y la comunidad) hicieron una clasificación de los diferentes tipos de responsabilidades, a fin de su priorización para poder desarrollar un plan de actuación de acuerdo a los intereses de la empresa y de los colectivos interdependientes con los que se relaciona. Dichos autores distinguen entre las responsabilidades primarias, inherentes a la actividad específica de la empresa, cuyo incumplimiento podría tener graves consecuencias para la pervivencia de la empresa; las secundarias, que buscan mejorar los efectos resultantes de esa actividad específica en los grupos sociales interdependientes con la empresa, más allá de unos mínimos exigibles; y las terciarias, que se extienden a actuaciones de la empresa encaminadas a mejorar determinados aspectos de su entorno social más allá de su actividad específica (Bestratén, M. y Pujol, L., 2003).

Aunque las responsabilidades primarias son por naturaleza prioritarias frente a las secundarias y éstas a su vez respecto a las terciarias, ante la complejidad de cada empresa y su entorno, es preciso actuar con flexibilidad buscando un cierto equilibrio con los grupos de interés, y cada empresa debe plantearse unas metas alcanzables, que no resulten irreales. Los objetivos que los diferentes grupos de interés tienen con la empresa pueden ser incompatibles entre sí, por lo que la empresa debe buscar una respuesta ponderada, que encuentre el equilibrio óptimo en su relación con ellos. Las responsabilidades 
variarán en función del tipo de empresa, si es grande o pequeña, si es multinacional o local, si actúa en países desarrollados o en vías de desarrollo, o según el tipo de actividad a que se dedique. Aunque en las páginas siguientes comentamos algunas de esas responsabilidades, sabemos que muchas veces cuando se habla de turismo sostenible o de responsabilidad social de las empresas turísticas se puede caer en señalar una larga lista de recetas y consejos sobre lo que debiera hacerse, esas recetas suelen ser conocidas, lo que importa es ponerlas en práctica.

Figura 1. Responsabilidades empresariales.

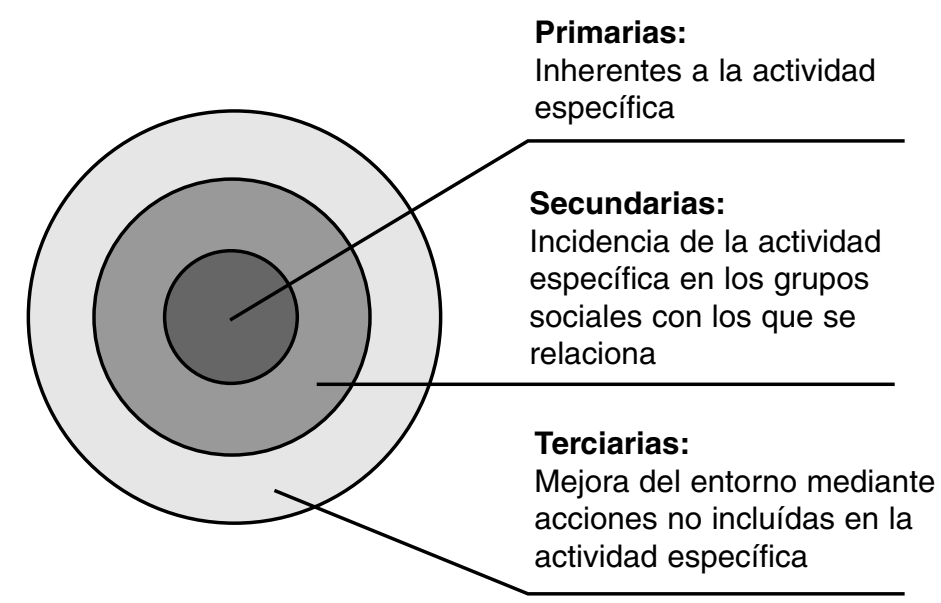

Fuente: Bestratén, M. y Pujol, L. (2003)

Entre las responsabilidades primarias están el servir a la sociedad con productos o servicios útiles y preservar el medio ambiente, con las prácticas más sostenibles. Las actuaciones de las empresas turísticas pueden dirigirse al ahorro de energía (minimizando su consumo, maximizando la eficiencia de las fuentes de energía utilizadas, o promocionando el uso de las renovables), de agua (promover todas las medidas posibles para su ahorro, implantar sistemas de reutilización, favorecer los cambios de comportamiento de los turistas), gestión de residuos (prevenir la generación de residuos desde el origen, reducir su cantidad al mínimo necesario, reutilización y reciclaje de productos y materiales), sustancias peligrosas (ausencia de vertido de aceites, grasas y sustancias tóxicas por los desagües, eliminación o reducción de productos con CFC o halones, análisis de aguas residuales y emisiones de calderas...) y compras (selección de productos que sean menos perjudiciales para el medio ambiente, en particular los de limpieza e higiene personal, equipos de mantenimiento y material de oficina).

Además, una empresa responsable debe serlo, en primer lugar, con sus trabajadores, y creando empleo. Lo que los ciudadanos valoran más de las empresas es la crea- 
ción de puestos de trabajo (Fundación Alternativas, 2008), y el buen trato a los trabajadores (véase Cuadro 1), asegurando unas condiciones de trabajo dignas, la mayor estabilidad posible en el empleo evitando el abuso de la contratación temporal, con sistemas de prevención de riesgos laborales, sin discriminación por razón de sexo, edad, raza..., y sin explotación o empleo de niños, favoreciendo la formación permanente de los trabajadores para asegurar su cualificación y empleabilidad en el futuro. Además, se debe favorecer la participación de los trabajadores, contar con sus sugerencias y aportaciones.

Cuadro 1: ¿Qué es lo más importante para los consumidores?

Corporate responsability: what is most important to customers?

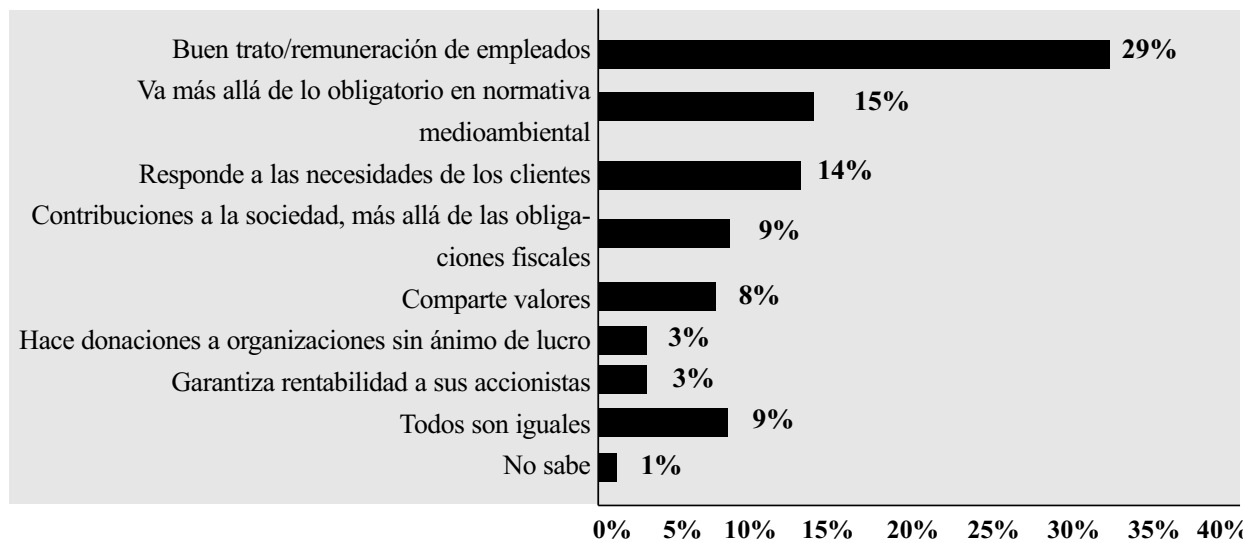

Fuente: Fundación Entorno (2008), a partir de Fleishman-Hillard/National Consumers League (2006), Rethinking Corporate Social Responsability.

Otras medidas relacionadas con los trabajadores (podríamos decir secundarias) son favorecer la conciliación de la vida laboral y familiar (por ejemplo, favoreciendo la estabilidad en el destino, permisos por circunstancias especiales, facilitar el cambio de turnos, excedencias con reserva...). Otra responsabilidad social de la empresa es la integración de colectivos más desprotegidos, como minusválidos o sectores con dificultades de inserción laboral. Por ejemplo, respecto a la inserción laboral de discapacitados, en España la Ley de Integración Social de Minusválidos (LISMI) obliga a las empresas con más de 50 trabajadores a reservar un $2 \%$ de sus puestos de trabajo para personas con discapacidad o, en su defecto, contratar o invertir en centros dedicados a la inserción laboral de este colectivo. Sin embargo las empresas incumplen los mínimos que marca la ley. En un reciente estudio publicado por la Fundación Mapfre (Guillén, C.. y Contreras, R., 2008) se indica que tan solo un $36 \%$ de las empresas españolas con más de 50 trabajadores tiene contratado a algún discapacitado, aunque la mayoría conozcan la LISMI. Los 
autores de ese estudio afirman que en algunos casos incluso se califica su trabajo de forma más excelente que el de las personas sin deficiencia, valorando su esfuerzo y las actitudes positivas hacia la empresa y hacia los clientes. Las empresas que han optado por la integración laboral de personas con discapacidad manifiestan estar muy satisfechas con su trabajo, señalan que apenas han tenido que realizar modificaciones en el lugar de trabajo y que no existen conflictos entre trabajadores con y sin discapacidad. Si las empresas conocieran mejor los beneficios que reporta la contratación de discapacitados, las subvenciones que pueden obtener para la adaptación de los puestos de trabajo, así como el nivel de motivación, fidelidad y esfuerzo continuo que demuestra un discapacitado a la hora de integrarse en el mercado laboral, las tasas de paro para dicho colectivo (muy altas hoy en día) disminuirían considerablemente.

Otras responsabilidades secundarias con los trabajadores son favorecer la iniciativa, autonomía y creatividad en el trabajo; facilitar el trabajo a tiempo parcial para aquellas personas que lo precisen, flexibilidad de horario laboral y en el disfrute de vacaciones, ayudas e incentivos a su formación, ayudas a planes personales de pensiones, ayudas por hijo en edad escolar, ayudas para vivienda, en especial cuando se requiera un cambio de municipio de residencia; organizar actividades recreativas y de ocio en la empresa; promover y facilitar su participación en programas de ayuda a la comunidad o al tercer mundo (Bestratén, M. y Pujol, L., 2003).

Especial interés tiene la relación con los proveedores y subcontratistas, sobre todo en países en vías de desarrollo, debiendo intensificarse la relación con aquellos que también empleen prácticas responsables. Además, muchas empresas hoteleras (como algunas españolas en América Latina) están subcontratando a otras empresas parte de su personal, por ejemplo para vigilancia y seguridad o limpieza. Esa estrategia divide a los trabajadores dentro de un mismo hotel y los sitúa en distintas situaciones contractuales, al mismo tiempo que diluye las responsabilidades de la empresa (Cañada, E., 2008).

Un aspecto muchas veces criticado de la industria turística es la aplicación del modelo "todo incluido", donde los turistas pagan un paquete completo y se les ofrecen todos los servicios sin relacionarse con la población local. Algunos entienden que este modelo supone una pérdida de beneficios para la población local y, como alternativa, se defiende la necesidad de aumentar los suministros locales, buscar proveedores locales de productos agrarios locales o de servicios locales. Las empresas turísticas pueden impulsar su responsabilidad social con la comunidad local aumentando su conexión con ella. Por un lado, una manifestación de esa responsabilidad es -en vez de recurrir a la contratación de personal venido de fuera- procurar emplear a todo el personal local que sea posible, lo que muestra a la comunidad local los beneficios de la empresa. Por otro lado, comprando más productos locales y utilizando servicios locales, favoreciendo la compra preferente a los proveedores locales. Por ejemplo, de la asociación con los agricultores locales las empresas pueden obtener una mayor diversidad de productos, y pueden conseguir precios más baratos, reduciendo los transportes y las llegadas de productos del exterior. Para los agricultores o para las pequeñas empresas de servicios, la conexión con las grandes empresas turísticas les puede aportar la posibilidad de vender más produc- 
tos, fomentar la producción de productos característicos de la zona o promocionar actividades culturales basadas en la tradición propia de la comunidad, actividades artesanales, gastronomía, música o fiestas locales, actividades deportivas o de entretenimiento.

Una forma de potenciar los beneficios económicos para la población más empobrecida de determinados destinos turísticos es ayudar al sector no estructurado de la economía, promoviendo e incrementando las conexiones con el sector estructurado del turismo (hoteles, otros alojamientos, restaurantes, touroperadores y transportes). Con ello se pueden desarrollar fuertes vínculos entre el turismo y otros sectores como la agricultura, la pesca, las manufacturas, la construcción o la artesanía. Para ampliar el alcance de las conexiones locales hay que crear vínculos empresariales mutuamente beneficiosos entre el sector estructurado y el no estructurado. Es preciso alentar a los centros de atracción de visitantes, los parques, los emplazamientos culturales y los hoteles a suministrar información sobre los productos y servicios locales que brinda la población más pobre (OMT, 2003). Los hoteles y touroperadores pueden ayudar a la población local a desarrollar productos y servicios turísticos y ayudarles a ello en cuanto a formación y marketing y, en algunos casos, ayudar a los proveedores locales a adaptarse para conseguir los requisitos de calidad que esperan los turistas. El desarrollo de productos complementarios aumentará también el atractivo del destino y el gasto de los turistas en la economía local. El sector ya consolidado también tiene interés en el desarrollo de productos complementarios: servicios turísticos (como paseos guiados y espectáculos) y bienes (particularmente artesanía y otras especialidades autóctonas), que complementan los servicios turísticos esenciales como son el transporte, las excursiones y alojamientos que forman el núcleo de la actividad turística. Estos productos complementarios brindan a menudo experiencias que no proporcionan los touroperadores y que enriquecen su producto ${ }^{10}$. Implantar políticas de responsabilidad social no tiene porque implicar costes y, cuando eso ocurre, pueden acabar siendo compensados por los beneficios. Muchos aspectos de esas políticas no suponen costes, sino sobre todo cambios de comportamiento.

En España hemos visto en los últimos años la aparición de políticas por parte del gobierno estatal y de los autonómicos, como el Plan de conciliación de la vida laboral y familiar, la Ley de Dependencia, la Ley para la igualdad efectiva entre hombres y mujeres, la incorporación de cláusulas sociales y medioambientales en la Ley de Contratos del Estado (que incluyen la creación de empleo, la contratación de personas con dificultades de inserción laboral, o compromisos medioambientales de las empresas adjudicatarias) o favorecer las compras públicas a empresas socialmente responsables. Estas medidas fomentan la responsabilidad social, aunque en la medida en que son regulaciones de las administraciones, se alejan de la "voluntaria" RSE.

Dentro de lo que es más propiamente RSE, en España hasta ahora el sector que más iniciativas ha llevado a cabo ha sido el de la banca (bancos y cajas que han desarrollado

10 Pueden verse algunos ejemplos en las páginas web de organizaciones vinculadas con el turismo justo y comunitario, como Redturs, Pro-poor Tourism, EchoWay, Tourism Concern, Fair Trade in Tourism South Africa, o Unión de Cooperativas Tierra y Agua (Nicaragua). 
proyectos para vivienda social, programas de conciliación de la vida familiar y profesional, financiación de proyectos de energía eólica o plantas de tratamiento de residuos); empresas de distribución como Eroski (campañas de comercio justo) o Alcampo (aumentando el número de empleados con discapacidades); o la empresa de transporte urgente MRW, integrando a personas con discapacidad (un 11\% de la plantilla en el año 2008) o favoreciendo la conciliación de la vida laboral con la familiar ${ }^{11}$. En el caso del turismo, a través de un estudio de Exceltur (Exceltur, 2003) conocemos algunas iniciativas de "acción social" que vienen desarrollando empresas españolas e internacionales (sobre todo las de alojamiento, pero también las de distribución, transporte, ocio, restauración y servicios complementarios), iniciativas como:

- programas de integración laboral de personas en riesgo de exclusión social (discapacitados, inmigrantes, mujeres víctimas de malos tratos...); la incorporación de personal nativo sin experiencia en el sector al que previamente se formó; o desarrollo de programas de igualdad de oportunidades de la mujer en el trabajo;

- contratar productos y servicios a centros especiales de empleo o de empresas de inserción;

- donación de productos o prestación de servicios gratuitamente o a precios especiales a organizaciones sociales, facilitar alojamiento o billetes gratuitos a niños enfermos y a sus familias en los desplazamientos necesarios para sus tratamientos, o colaboración con ayuntamientos para ofrecer alojamiento gratuito a mujeres víctimas de malos tratos hasta que puedan ir a una casa de acogida;

- en algunos casos, las empresas turísticas conceden microcréditos a personas en países en vías de desarrollo para financiar la compra de materiales y otros gastos relacionados con la puesta en marcha de actividades nuevas o la mejora de actividades existentes;

- promoción del voluntariado de sus empleados;

- programas de becas para la formación de hijos de empleados, o para la formación de niños y jóvenes en lugares donde abandonan los estudios para ponerse a trabajar;

- colaboración en programas para proteger la tradición cultural y natural;

- eliminación de barreras arquitectónicas en sus instalaciones y facilitar la movilidad de personas discapacitadas;

- incluir entre los proveedores habituales a pequeñas empresas locales o artesanales;

- dedicar recursos ayudando a las organizaciones locales a construir viviendas asequibles, revitalizando zonas de bajos recursos, mejorando la infraestructura, el

11 Para el director de Recursos Humanos del Grupo Vips "las personas con discapacidad y aquellas pertenecientes a colectivos en riesgo de exclusión (mayores de 45 años, víctimas de violencia de género...) “son más productivas y más fieles a la empresa que la media de la población”. Declaraciones de Miguel Ángel García, en "Ser Responsable", 19 feb. 2008. 
tratamiento de aguas residuales o apoyando tiendas de artesanía local (Exceltur, 2003).

\section{ALGUNAS INICIATIVAS PARA FOMENTAR LA RSE}

Algunos organismos internacionales han puesto en marcha iniciativas para fomentar comportamientos responsables por parte de las empresas. Éstas pueden adherirse a dichas iniciativas, comprometiéndose a cumplirlas.

- El Pacto Mundial de las Naciones Unidas (Global Compact), iniciado en 1999, cuenta con una serie de principios voluntarios en áreas de derechos humanos, trabajo, medio ambiente y lucha contra la corrupción. Se establecen políticas de diálogo entre las empresas y sus stakeholders. Anualmente las empresas adheridas deben compartir ejemplos de sus acciones concretas donde se aplique al menos uno de los principios del Pacto (actualmente las empresas españolas encabezan el ranking de países firmantes del Pacto).

Cuadro 1: Los diez principios del Pacto Mundial

\section{Derechos Humanos}

- Principio I: Apoyar y respetar la protección de los derechos humanos proclamados en el ámbito internacional.

- Principio II: Asegurarse de no ser cómplice en abusos a los derechos humanos

\section{Normas Laborales}

- Principio III: Respetar la libertad de asociación y el reconocimiento efectivo del derecho a la negociación colectiva.

- Principio IV: Eliminar todas las formas de trabajo forzoso u obligatorio.

- Principio V: Abolir de forma efectiva el trabajo infantil.

- Principio VI: Eliminar la discriminación con respecto al empleo y la ocupación

\section{Medio Ambiente}

- Principio VII: Apoyar los métodos preventivos con respecto a problemas ambientales

- Principio VIII: Adoptar iniciativas para promover una mayor responsabilidad ambiental.

- Principio IX: Fomentar el desarrollo y la difusión de tecnologías inofensivas para el medio ambiente.

\section{Anticorrupción}

- Principio X: Las empresas deberán trabajar contra la corrupción en todas sus formas, incluyendo la extorsión y el soborno.

Fuente: www. pactomundial.org

- Las Directrices de la OCDE para empresas multinacionales son recomendaciones hechas por los gobiernos a las empresas, buscan establecer políticas voluntarias que promuevan la transparencia empresarial en materia de relaciones laborales 
(con el respeto al derecho a ser representados por sindicatos, emplear a personal local...), gestión medioambiental, intereses de los consumidores, lucha contra la corrupción, extensión de las exigencias propias a los proveedores y subcontratistas. Resulta muy fácil adherirse a esas Directrices, pero resulta difícil el control efectivo de su cumplimiento por los afectados o interesados (Fuentes et al., 2006).

- Normas de la OIT, que identifican los derechos fundamentales en el trabajo, como la libertad de asociación y el derecho a la negociación colectiva, la eliminación de todas las formas de trabajo forzado u obligatorio, la abolición del trabajo infantil, y la eliminación de la discriminación. Son normas que todos los gobiernos debían considerar vinculantes, pero que luego muchos incumplen. La Declaración Tripartita sobre empresas multinacionales estipula una serie de principios centrados en cuestiones laborales (condiciones de trabajo, libertad sindical, negociación colectiva, salarios, seguridad e higiene, igualdad de oportunidades, edad mínima...) y va dirigida a gobiernos, empresas y trabajadores ${ }^{12}$.

- La Comisión Europea publicó en el año 2001 el "Libro Verde: Fomentar un marco europeo para la responsabilidad social de las empresas", como una propuesta de promoción de la RSE a nivel europeo e internacional. Establece una nueva estrategia global europea para esta década cuyos objetivos son: poseer la economía basada en el conocimiento más competitiva y dinámica del mundo, capaz de conseguir un crecimiento económico sostenible, con mayores y mejores empleos, y una mayor cohesión social. Para las empresas supone el reto de dar respuesta a metas relativas a responsabilidades económicas, sociales y medioambientales. Para ello en los balances anuales de las empresas se utiliza el triple reporting o informes de "triple cuenta de resultados" (económico, social y medioambiental, más allá del tradicional informe financiero anual). Las dimensiones más importantes a considerar son: gestión de recursos humanos, salud y seguridad en el lugar de trabajo, la adaptación al cambio, la gestión del impacto ambiental y de los recursos naturales; las relaciones con las comunidades locales, las políticas hacia los socios, proveedores y comunidades, el respeto a los derechos humanos; y la extensión de estas responsabilidades a toda la cadena de proveedores. Como ya comentamos, la Unión Europea defiende que el desarrollo de políticas de RSE sea a base de acciones voluntarias de las empresas, pero ha desarrollado herramientas, guías prácticas, modelos teóricos y ejemplos de indicadores para medir los "intangibles" de la empresa ${ }^{13}$.

- Desde las administraciones públicas caben muchas iniciativas para fomentar la responsabilidad social. Frente a los que consideran que la RSE debe ser una opción voluntaria y que introducir regulaciones por parte de las administraciones públicas

12 En estos últimos años vemos, por ejemplo, la aparición de numerosas críticas denunciando el comportamiento fuertemente antisindical de algunas cadenas hoteleras españolas en sus establecimientos situados en América Latina.

13 Pueden verse en la página web de CSR Europe. 
supone su desnaturalización, hay quienes creen que las administraciones deben fomentar la RSE, regulando especialmente todo lo referente a la transparencia y a la verificación externa. Por otro lado, las administraciones -además de regular la economía mediante leyes, incentivos y subvenciones- también tienen una participación activa en el mercado como consumidoras (comprando productos, contratando servicios y encargando obras), pudiendo influir en las empresas a través de su política de adquisición. Por ejemplo, pueden fomentar la compra pública sostenible, habida cuenta que las administraciones son las principales contratantes de obras y servicios y su papel puede ser determinante en el establecimiento de pautas de conducta en las empresas, más allá de la tradicional función fiscalizadora. Se trataría de hacer compras y contrataciones que primen la RSE exigiendo determinados requisitos a las empresa que opten a contratar con las administraciones; en el caso del turismo p. ej. utilizar para las actividades del gobierno únicamente alojamientos que demuestren que cumplen los criterios de sostenibilidad. Con ello hacen uso de su poder como consumidores para impulsar la responsabilidad social de sus proveedores y subcontratistas. Los criterios más utilizados hasta ahora han sido los medioambientales, con las llamadas “compras verdes", si bien se están empezando a incluir criterios sociales ${ }^{14}$. La magnitud del mercado de compra pública es considerable. Si las entidades públicas comienzan a demandar productos y servicios con unos estándares ambientales, sociales y éticos garantizados, las empresas se verán obligadas a revisar su cadena de aprovisionamiento, invertir en innovación y revisar sus políticas de empleo. Este camino permitiría incrementar los niveles de aplicación de las prácticas responsables en el sector empresarial; pondrían de manifiesto el compromiso adquirido por los organismos públicos en materia de RSE; además de mejorar la calidad de vida de la ciudadanía: las prácticas de consumo responsable priman el suministro de bienes y servicios de mayor calidad, incluyen políticas de inclusión social, igualdad de oportunidades, empleo, protección ambiental, desarrollo sostenible y mejora de los servicios públicos ${ }^{15}$.

\section{LA AUTORREGULACIÓN DE LAS EMPRESAS TURÍSTICAS}

La autorregulación se refiere a iniciativas voluntarias promovidas por compañías individuales, asociaciones sectoriales o de la industria en su conjunto, que van más allá

\footnotetext{
14 En España en el año 2005 se hicieron públicos los nuevos pliegos de contratación del Ministerio de Fomento, que incluían objetivos sociales, solicitándose a las empresas que cumplieran ciertas condiciones en la fase de ejecución de las obras: estabilidad en el empleo (el personal laboral fijo debía superar el $40 \%$ de la plantilla), aumentar el empleo femenino y el de discapacitados, así como el aumento de la salud y seguridad en el trabajo.

15 NEXOS Compra Responsable. Boletín $n^{\circ}$ 2, otoño 2007. La compra responsable es una eficaz herramienta para desarrollar la responsabilidad social, no sólo en el sector público, sino en todo tipo de empresa, pequeña, mediana o grande. En este ámbito cabe destacar iniciativas como las de la Asociación de Profesionales de Compras, Contratación y Aprovisionamientos de España (AERCE), editando una "Guía Técnica para la Compra Sostenible" dirigida a los compradores de todas las empresas, impulsando las compras sostenibles en los aspectos ambientales, sociales y éticos.
} 
de la legislación existente en su compromiso de mejorar su comportamiento sostenible. Frente a los instrumentos regulativos, los instrumentos voluntarios prometen una mayor rapidez y eficacia para alcanzar los objetivos con un menor coste. Las empresas comprometidas deciden sobre los objetivos a cumplir, cómo cumplirlos y cómo realizar el seguimiento, la verificación y la comunicación hacia el exterior. En un intento de mostrar su responsabilidad ante los impactos negativos sobre el entorno natural y sociocultural, en los últimos años el sector turístico ha creado y adoptado múltiples iniciativas voluntarias relacionadas con la sostenibilidad. Los instrumentos de autorregulación del sector suelen ser preferidos por las empresas como alternativa a la regulación obligatoria impuesta desde fuera de la industria (por gobiernos, organismos internacionales...), y a menudo son propuestos precisamente para anticiparse a la imposición legal en un determinado aspecto. Muchos de estos instrumentos son de aplicación general a todo tipo de industrias, otros son específicos de la turística.

a/ Códigos de conducta: son guías y recomendaciones que la misma industria establece o ayuda a establecer como líneas de actuación deseables para mejorar el comportamiento sostenible de la empresa. Desde los años ochenta, y sobre todo en los noventa, surgieron códigos de conducta promovidos o dirigidos al sector turístico. Hoy hay una gran variedad (a nivel internacional, nacional o regional), desarrollados por organizaciones gubernamentales, asociaciones empresariales u ONGs que, al margen de su enfoque y grado de compromiso exigido, pueden servir como guía general en cualquier tipo de turismo y entorno. Los códigos de conducta son fáciles de emplear y contribuyen a mejorar la imagen de las organizaciones. Algunos de los más conocidos son el "Código de conducta contra el turismo sexual infantil", promovido por la organización ECPAT, junto a UNICEF y OMT, y que lucha contra la prostitución infantil ligada al turismo, sobre todo en el Sudeste Asiático ${ }^{16}$; y el "Código Ético mundial para el turismo" elaborado por la OMT para que los diferentes actores de la industria turística asuman e incorporen los principios éticos en sus prácticas habituales, pero que carece de poder vinculante, siendo sólo exigible desde el momento de su introducción en derecho interno por cada uno de los Estados que forman parte de la OMT, a través de disposiciones nacionales de carácter obligatorio ${ }^{17}$. La principal limitación de los códigos es el escaso control que desde el exterior de la empresa se puede ejercer sobre su cumplimiento efectivo.

b/ Guías de buenas prácticas: las buenas prácticas son medidas implantadas por una empresa para controlar o reducir los impactos de su actividad y favorecer una gestión más responsable y eficiente. Existen numerosas actuaciones que, sin coste alguno o con pequeñas inversiones, alcanzan un efecto considerable sobre la calidad ambiental y

16 En el año 2008 se habían adherido al Código más de 750 empresas de todo el mundo (cadenas hoteleras, operadores turísticos, agencias de viajes, líneas aéreas, organizaciones empresariales..), tres de ellas españolas: Sol Meliá Hotels \& Resorts, Barceló Hotels \& Resorts y Viajes Mogador.

17 El gobierno español se adhirió a los principios del Código Ético en el año 2005, comprometiéndose simplemente a "difundir" sus principios, dejando escapar la ocasión de introducir el Código en una norma interna que lo hubiera hecho exigible para las empresas turísticas españolas: Maa D. López Gómez (2007). 
el balance económico de la empresa (ahorros de consumo de energía, agua, reducción de residuos...). Así, Green Globe promueve las buenas prácticas ambientales en todas las actividades ligadas al turismo, y Rainforest Alliance editó en 2005 "Buenas prácticas para el Turismo Sostenible. Una guía para el pequeño y mediano empresario", organizadas en tres áreas: ambiente, aspectos socioculturales y aspectos económicos ${ }^{18}$. En el caso español, estudiado por Silvia Ayuso, las guías suponen para las empresas un ahorro de costes a medio/largo plazo, las actuaciones dirigidas a influir en el comportamiento rutinario del trabajo suelen tener un nulo o bajo coste económico, pero la aplicación de medidas de mayor calado (p. ej. instalar placas solares o reutilizar las aguas grises) requiere la compra de equipos y maquinarias costosas. Las medidas implantadas para mejorar y optimizar la eficiencia de las instalaciones pueden tener un periodo de amortización menor o mayor, pero por regla general no sería superior a 8 años. Las áreas en las que más actuaciones llevan a cabo los hoteles españoles son las encaminadas a reducir costes a corto plazo, en las que se espera una rápida amortización de las inversiones realizadas (ahorro de energía, agua) o las más visibles para el turista (recogida selectiva de residuos), pero las dirigidas a largo plazo se practican menos. Teóricamente la comunicación de las buenas prácticas tiene un efecto positivo en la imagen de la empresa y puede ser utilizada como herramienta de marketing. Las previsiones muestran una creciente preocupación de los turistas por cuestiones ambientales a la hora de seleccionar un destino o alojamiento. Sin embargo, aunque puede ser que los turistas valoren el esfuerzo hecho por el hotel, no parece ser un factor decisivo a la hora de elegir hotel, y -al menos en España- los empresarios no aprecian un incremento de ventas por haber introducido mejoras. Hasta ahora los clientes no parecen escoger un hotel porque sea más ecológico, sino porque da mejor servicio, mejor precio o está situado en un lugar determinado (Ayuso, S., 2003).

c/ Las ecoetiquetas: son otro instrumento voluntario que otorga un distintivo a los productos o servicios que, en comparación con otros que cumplen la misma función, son menos perjudiciales para el medio ambiente. En el sector turístico las ecoetiquetas sirven para suministrar información sobre el comportamiento ambiental de las empresas, de modo que los clientes puedan reconocer en un producto o servicio ecoetiquetado que cumple unos requisitos, y que eso influya en su decisión de compra. Además, sirven para mejorar el comportamiento ambiental y aumentar la concienciación de las partes interesadas: empresas, autoridades locales y consumidores; ayudar a las empresas a identificar puntos críticos, e implantar soluciones ecoeficientes basadas en medidas de ahorro y tecnologías limpias. Las ecoetiquetas turísticas se aplican sobre todo a instalaciones y alojamientos: hoteles, pensiones, campings, pero también a restauración, puertos deportivos, operadores turísticos, agencias de viaje, compañías de transporte, playas, parques naturales o municipios enteros. Muchas fueron desarrolladas en los años noventa a nivel

18 En España, aparte de algunas entidades privadas, han sido las administraciones públicas las que han difundido las buenas prácticas para los hoteles. Muchas Consejerías de Medio Ambiente autonómicas han publicado manuales con ejemplos de buenas prácticas para los hoteles, y que suelen incluir referencias a la legislación ambiental del Estado y de la Comunidad Autónoma (Ayuso, 2003). 
local o regional, promocionadas por asociaciones empresariales. En los últimos años se han creado más las de carácter nacional e internacional que, en algunos casos, parece que desplazarán a las de ámbito menor.

Algunas ecoetiquetas conocidas son Green Globe 21, sistema de certificación internacional, que otorga su etiqueta a distintos sectores como hoteles, destinos, tour operadores o aeropuertos. Cuenta con tres niveles según el grado de actuación y su correspondiente evaluación y auditoría, el nivel más elevado implica implantar un Sistema de Gestión Ambiental conforme a la norma ISO 14001. La Unión Europea buscó contrarrestar la gran cantidad de etiquetas ecológicas existentes con una europea, la Etiqueta Ecológica Europea (la "Flor") como sistema voluntario para certificar productos y servicios respetuosos con el medioambiente, incluidas las empresas de alojamientos, y para proporcionar a los consumidores información verificable. Los productos que obtienen la etiqueta son examinados por expertos independientes. Establecimiento Eco-comprobado (Öko-Proof-Betrieb) fue desarrollada por el grupo alemán TÜV, como certificación específica para hoteles y restaurantes. Ofrece un modelo más sencillo y práctico que las certificaciones ISO 14001 o EMAS, estableciendo unos estándares adecuados para asegurar el prestigio del certificado. Se concede en función de una evaluación a la empresa a partir de un cuestionario específico para el sector sobre áreas que debe comprender una buena gestión medioambiental en un hotel o restaurante ${ }^{19}$.

d/ Certificaciones de sistemas de gestión ambiental: los sistemas de gestión ambiental han demostrado su eficacia en la mejora del comportamiento ambiental de las empresas. Existen dos normas de carácter voluntario para implantar esos sistemas: la norma de ámbito internacional ISO 14001, y -en Europa- el reglamento EMAS (EcoManagement and Audit Scheme). Los dos son similares, EMAS un poco más exigente, porque obliga a hacer una Declaración Ambiental. Están muy extendidos en las empresas del sector turístico. A las organizaciones que los implantan les permiten garantizar una mejor gestión ambiental y optimizar su comportamiento ambiental (con la mejora de la competitividad de la compañía, mediante la racionalización del uso de recursos y la reducción de residuos), así como demostrar públicamente su compromiso por la preservación del entorno (mejora de la imagen frente a sus clientes, proveedores, administración y personal interno). La gestión medioambiental debe estar presente tanto en los órganos de decisión de la empresa como en los trabajadores y subcontratistas.

No prescriben requisitos de actuación ambiental concretos, salvo la obligación de cumplir todos los requisitos legales y promover la mejora continua. Frente a la gran can-

19 Hay muchas otras iniciativas relacionadas con las ecoetiquetas, como la Carta Europea de Turismo Sostenible en Espacios Protegidos, que es un certificado que la Federación Europarc (Federación de Parques Naturales y Nacionales de Europa) otorga a los espacios naturales europeos que gestionan sus áreas con criterios de sostenibilidad y en armonía con la actividad turística. Busca la colaboración entre las instituciones gestoras de los espacios protegidos, las empresas turísticas situadas en esos espacios y los organizadores de viajes hacia ellos, para fomentar un turismo de acuerdo con la gestión sostenible de los recursos naturales de esos espacios. Cualquier espacio protegido europeo puede adherirse a la Carta.

Existe una gran variedad de etiquetas para productos y oferta turísticas que se basan en criterios medioambientales y de calidad, pero prácticamente no existen etiquetas basadas en aspectos sociales de la oferta turística. 
tidad de leyes y normas nacionales, autonómicas o municipales, implantar uno de esos sistemas supone para las empresas evitar posibles riesgos por incumplimiento de alguna de ellas. Además, el certificado expedido por un organismo independiente (caso de ISO 14001) o la inclusión en un registro europeo de empresas (EMAS) se percibe como un reconocimiento oficial a su compromiso con el medio ambiente. En el informe "Sostenibilidad en España 2006" se indicaba que de todos los sectores económicos, era el de la hostelería y servicios turísticos el que contaba con mayor implantación de sistemas de gestión ambiental -ya sean ISO 14001 o EMAS-, superando el 20\%, lo que es una demostración clara de la evolución hacia comportamientos más limpios y respetuosos con el medio ambiente ${ }^{20}$.

e/ Certificaciones de carácter integral y de auditoría social: Después de los éxitos alcanzados con las certificaciones de sistemas de gestión ambiental, se han dado pasos hacia la introducción de certificaciones que toman en consideración la gestión en cuestiones sociales. Es el caso de la norma SA8000, que comentamos en el epígrafe siguiente, o los intentos de crear certificaciones de carácter integral como el futuro estándar ISO 26000 de Responsabilidad Social, que se espera que vea la luz en el año 2010, y será una guía de recomendaciones, orientaciones, no de requisitos y obligaciones, y establecerá una pauta común de conceptos, definiciones y métodos de evaluación.

Tendrá una aplicación voluntaria y pretende ayudar a implantar un sistema de gestión de la responsabilidad social, reconociendo a ésta como un elemento esencial en el buen desempeño de toda organización. No será certificable ni tampoco una norma de sistema de gestión como la norma ISO 14001, que implica una estructura organizacional y procedimientos de planificación específicos para su implementación, pero brindará una guía práctica específica sobre cómo integrar e implementar la Responsabilidad Social en la organización con un enfoque stakeholder (Veloz, 2008).

Se confía en que ISO 26000 impulse a las empresas a emprender actividades que vayan más allá del cumplimiento de la ley. La ISO 26000 explica los temas fundamentales involucrados en la responsabilidad social: gobernanza organizacional, derechos humanos, prácticas laborales, el medio ambiente, prácticas operacionales justas, temas de consumidores y desarrollo e involucramiento de la comunidad ${ }^{21}$. Estará destinada a todo tipo de organizaciones (públicas y privadas, organizaciones no gubernamentales y sindicatos). La Guía de ISO podrá ayudar a perfilar y dar significado a las políticas,

20 En 2007 más de 900 empresas españolas figuraban en el sistema EMAS, lo que convertía a España en el segundo país de la Unión Europea con más empresas inscritas en este registro después de Alemania (que contaba con unas 1.980). En los últimos años ha aumentado sobre todo la presencia del sector servicios y en particular las empresas turísticas y organismos públicos, formando parte del registro 217 hoteles.

21 La ISO 26000 incorporará las declaraciones y los tratados relevantes de las Naciones Unidas y sus organizaciones, en especial de la Organización Internacional del Trabajo (OIT), con la cual ISO estableció un memorándum de entendimiento a fin de asegurar la conformidad del estándar con los estándares internacionales del trabajo de dicha organización. También firmó este acuerdo con el Global Compact de la ONU, según el cual ISO 26000 debe ser compatible y complementar los diez principios del Global Compact. Además cuenta con la colaboración de otras organizaciones, como el Global Reporting Initiative (GRI) o el Social Accountability International (SAI) que, aunque no han firmado dicho memorándum, participan activamente en el proceso. 
estrategias y procedimientos de responsabilidad social tanto de grandes empresas como de las pequeñas y medianas, y se espera que sea un instrumento útil para mejorar el desempeño de todas aquellas organizaciones que actualmente carecen de procesos para implementar y evaluar aspectos en materia de responsabilidad social.

Por otro lado, la Norma SGE 21 es una certificación en Gestión Ética y Responsabilidad Social. Busca integrar un sistema de gestión de la calidad, de gestión medioambiental, de prevención de riesgos laborales y otros aspectos derivados del compromiso de la empresa con la responsabilidad social. Impulsada por Forética, está implantada en empresas españolas y ha iniciado su extensión a países latinoamericanos. Actualmente está en su tercera versión, la SGE 21: 2008. Es la única norma certificable en RSC de carácter integral en el mundo (ya que la SA8000 sólo lo es a nivel parcial, e ISO 26000 es una guía y no será norma ni será verificable).

\section{LA NORMA SA8000}

La norma SA8000 (Social Accountability, Auditoría Social) es un instrumento de certificación de la responsabilidad social de las empresas, diseñado según el modelo de las normas ISO 9001 e ISO 14001, y que le permite a la empresa desarrollar un sistema de gestión social. Busca asegurar una producción ética de bienes y servicios, poniendo énfasis en el respeto a los derechos humanos y las condiciones de trabajo, especialmente en empresas que operan en países poco desarrollados, demostrando a los grupos de interés el compromiso de la empresa con un tratamiento ético de sus empleados.

En 1997, en EE.UU., se creó la CEPAA (Council on Economic Priorities Acreditation Agency), ahora llamada Social Accountability International, SAI, con un panel de expertos compuesto por representantes de organizaciones que representaban a diversas partes interesadas (sindicatos, fabricantes, minoristas, organismos académicos, ONGs y empresas de consultoría y certificación). Su propósito era redactar un código universal de prácticas para las condiciones de trabajo en industrias manufacturadas, de modo que los consumidores pudieran estar seguros de que las mercancías que compraban habían sido producidas de acuerdo con estándares socialmente reconocidos. Por entonces no había consenso respecto a lo que constituía exactamente una política socialmente responsable, de manera que los innumerables códigos eran dispares y difíciles de auditar.

La empresa a acreditar debe cumplir la legislación nacional del país en que opere, y cualquier otro derecho aplicable establecido en códigos internacionales, como la Declaración Universal de los Derechos Humanos, la Convención de Naciones Unidas sobre los Derechos del Niño, la Convención de Naciones Unidas sobre la Eliminación de toda forma de Discriminación contra la Mujer, y diversas convenciones de la Organización Internacional del Trabajo (OIT) ${ }^{22}$. Por tanto, la norma SA8000 establece unos requisitos de

22 Las siguientes Convenciones y Recomendaciones de la OIT: Convenciones 29 y 105 (Trabajos forzados y esclavitud), Convención 87 (Libertad de asociación), Convención 98 (Derecho de negociación colectiva), Convenciones 100 y 111 (Igual remuneración para trabajadores y trabajadoras, por trabajo de igual valor; 
responsabilidad social a verificar, que se organizan en 8 cláusulas relacionadas con los derechos laborales básicos y el bienestar del trabajador: trabajo infantil, trabajos forzados, salud y seguridad en el trabajo, libertad de asociación y derecho a la negociación colectiva, no discriminación, medidas disciplinarias, jornada de trabajo y remuneraciones. Además, la empresa se compromete a establecer y mantener procedimientos adecuados para evaluar y seleccionar a los proveedores/subcontratistas en base a su capacidad para cumplir con los requerimientos de la norma SA8000. Para ello mantendrá registros adecuados y realizará pruebas razonables del compromiso de los proveedores y subcontratistas, incluyendo su compromiso escrito de acatar todos los requerimientos de la norma.

La norma es de aplicación universal, en cualquier país y sector. Para recibir la certificación SA8000 las empresas deben aceptar una auditoría externa. Esto permite que tanto los consumidores como la sociedad en general puedan identificar claramente a aquellas empresas que logran condiciones de trabajo dignas. El reconocimiento se formaliza con la entrega de un certificado y el permiso de utilizar la marca del certificado en los documentos de la empresa (lo que está sometido a ciertas condiciones especificadas por SAI). Como en toda auditoría, en la certificación de la norma intervienen una serie de elementos: un certificador (experto en la norma, conocedor de la empresa que tiene que analizar, y que realiza un trabajo externo de comprobación), una organización que desea conseguir la certificación, pruebas que revelen una evidencia suficiente, en las que el experto debe basar su trabajo; un documento que resume la opinión del experto y del que éste es responsable; y el informe (que se dirige a los interesados -clientes, propietarios de la empresa, empleados, autoridades públicas, etc.- en conocer si la empresa cumple o no los requisitos).

La norma SA8000 o similares puede aportar ventajas a la empresa, a los trabajadores, a los clientes y a los stakeholders. Por ejemplo, para la empresa supone contar con la confianza de los consumidores e inversores. Para los trabajadores de los países menos desarrollados supone una mejora de las condiciones de trabajo, lo que podrá influir en la mejora de su poder adquisitivo, el aumento de la productividad o en la reducción de los accidentes de trabajo. Para los trabajadores de los países más desarrollados puede suponer una forma de limitar la deslocalización de empresas, con el traslado de fábricas de esos países a otros más atrasados y con mano de obra más barata. Para los clientes supondría consumir productos y servicios realizados por trabajadores en condiciones más dignas, asegurándose que detrás de esos productos y servicios no hay situaciones injustas. Al ser de verificación externa, permite a los consumidores, turistas en nuestro caso, identificar claramente las empresas responsables con sus trabajadores. Sin embargo, la norma es hasta ahora poco conocida, las empresas no sólo tienen que realizar el esfuerzo de adaptarse a sus requisitos sino que también tienen que comunicar a sus clientes las ventajas y compromisos que supone tal norma. Además, la certificación es cara y puede ser inaccesible para algunas empresas.

Discriminación), Convención 135 (Convención sobre los representantes de los trabajadores), Convención 138 y Recomendación 146 (Edad mínima), Convención 155 y Recomendación 164 (Salud y seguridad en el trabajo), Convención 159 (Rehabilitación vocacional y empleo de personas discapacitadas), Convención 177 (Trabajo en el hogar), Convención 182 (Peores Formas de Trabajo Infantil). 
El grado de implantación es aún modesto. En junio de 2009 el número de empresas certificadas con la norma era de unas dos mil de 64 países (alcanzando a 1.200.000 trabajadores). Por países, destacaba Italia (con 875 empresas), seguida por India (396), China (231), Brasil (97), Pakistán (87), Vietnam (47). España contaba con 23 empresas certificadas. El grupo más importante de empresas certificadas era el de las medianas, pertenecientes a sectores industriales (especialmente confección, textil, química y transporte). A pesar de ser un instrumento apto para ser aplicado en el sector turístico, hasta ahora las empresas del sector no lo han implantado. Aunque es todavía pronto para que la norma sea lo suficientemente conocida, exigida y valorada, normas como ésta u otras de contenidos similares pueden acabar imponiéndose y generalizándose en las organizaciones de la misma manera y acaso con mayor celeridad que las normas de calidad (Fuentes, F. et al., 2006) ${ }^{23}$.

Cuadro 2. Requisitos de responsabilidad social de la norma SA8000.

\section{TRABAJO INFANTIL}

1.1. La empresa promete no emplear trabajo infantil 1.2. La empresa proveerá educación para los menores que se encuentran trabajando por debajo de la edad mínima legal para el trabajo

1.1. La empresa asegura que ningún trabajador en edad escolar trabaje durante horas de clase o que las horas acumuladas que se dediquen al trabajo, la escuela y el transporte no excedan de 10 horas diarias

1.2. Los niños no serán expuestos a condiciones que pongan en riesgo su salud ni su seguridad

\section{TRABAJOS FORZADOS}

2.1. La empresa no contratará ni apoyará el uso de trabajo forzoso o contratado bajo amenaza; ni permitirá que ningún trabajador esté obligado a “depositar" dinero o entregar sus documentos de identidad como condición para ser contratado.

\section{IGUALDAD Y NO DISCRIMINACIÓN}

5.1. La empresa se compromete a no ejercer ni apoyar prácticas discriminatorias (basadas en raza, sexo, discapacidad, origen nacional, religión, orientación sexual, edad, afiliación política, religiosa...)

5.2. No habrá interferencia con los derechos individuales; p. ej. respetará las creencias religiosas 5.3. No se permitirán comportamientos de hostigamientos hacia los trabajadores

\section{MEDIDAS DISCIPLINARIAS}

6.1. La empresa no practicará ni apoyará el uso de violencia o coerción física o psicológica, ni el abuso verbal

\subsection{Prohibición de castigos físicos}

6.3. Compromiso de no practicar deducciones salariales arbitrarias, p. ej. por causa de enfermedad o por no trabajar horas extras

6.4. No amenaza de despido o de daño personal

23 Por su parte la organización AccountAbility ha desarrollado la norma AA1000, como referente en aseguramiento de sostenibilidad, es auditable y está inspirada en la norma ISO 14000. Incluye procedimientos similares a la norma SA8000, pero hace caer un mayor peso del proceso de verificación en los stakeholders. Está dirigida a las entidades verificadoras, estableciendo los requerimientos mínimos para cada elemento del proceso de verificación. La versión más reciente, de 2008 (que revisa la anterior de 2003) facilita un modo de usar y poner en contexto los diferentes sistemas de certificación dedicados a dimensiones específicas de la sostenibilidad como pueden ser la gestión sostenible de la madera, los sellos de comercio justo o los sistemas de gestión ambiental. Además, constituye una plataforma creíble y objetiva para alinear los aspectos sociales y ambientales de la sostenibilidad con aquellos del reporting financiero y la verificación. 


\section{SALUD Y SEGURIDAD}

3.1. La empresa proveerá un ambiente laboral seguro y saludable

3.2. Un gerente debe ser designado como encargado de la salud y seguridad

3.3. Se proveerá capacitación en seguridad regularmente

3.4. La empresa se compromete a tomar una posición proactiva con el fin de resolver potenciales problemas de salud y seguridad

3.5. La empresa proveerá servicios higiénicos en condiciones limpias y agua potable; y los dormitorios, en el caso de que se provean, deberán estar en condiciones limpias

LIBERTAD DE ASOCIACIÓN Y DERECHO A LA NEGOCIACIÓN COLECTIVA

4.1. La empresa respetará el derecho de sus empleados a formar sindicatos y a negociar colectivamente

4.2 En el caso de que los sindicatos o la negociación colectiva se encuentren legalmente restringidos, la empresa se compromete a facilitar otras formas paralelas de libre asociación

4.3. La empresa se compromete a asegurar que no haya discriminación contra los representantes sindicales, y que éstos tengan acceso a los trabajadores en el lugar de trabajo

\section{JORNADA DE TRABAJO}

7.1. La empresa cumplirá con la legislación nacional y las normas sectoriales sobre la jornada laboral. Máximo legal de hasta 48 horas semanales. Por lo menos un día de descanso semanalmente

7.2. Se compromete a asegurar que las horas extras:

- serán pagadas con una sobretasa (paga superior a la de las horas normales)

- no deben de exceder de más de 12 horas semanales

- no se exigirán de forma regular

\section{REMUNERACIONES}

8.1. El salario debe cumplir con los requerimientos legales y ser suficiente para cubrir las "necesidades básicas" y algún ingreso complementario 8.2. El salario no deberá ser retenido por motivos disciplinarios, y deberá ser detallado y presentado de una forma que sea comprensible para el trabajador y pagado en efectivo o mediante un cheque o depósito bancario

8.3. La empresa garantizará que no existan prácticas de contratación irregular, o de falsificación de los programas de aprendizaje, dirigidas a evitar el cumplimiento de las obligaciones legales relativas a los derechos laborales y a la seguridad social

Fuente: Fuentes, F. et.al. (2006).

\section{LAS MEMORIAS DE SOSTENIBILIDAD Y LA GUÍA GRI}

Otra de las iniciativas destacadas para el fomento de la responsabilidad social es la emisión de informes sociales, presentando, junto al informe económico-financiero, una memoria de sostenibilidad o de RSE, que dé respuesta a la demanda de información sobre los aspectos sociales y medioambientales de las empresas. Algo que en los últimos años está haciendo un número creciente de empresas.

En el Libro Verde de la Comisión Europea se hablaba de la necesidad de contar con un documento que comunicara los resultados de una evaluación del impacto social, y de apoyar planteamientos de buenas prácticas por lo que respecta a la evaluación de la rentabilidad y la verificación independiente de las prácticas de responsabilidad social en la empresa, garantizando así su eficacia y credibilidad. La elaboración de estas memorias 
es una herramienta que ayuda a mejorar la gestión de la empresa, facilitando un mejor conocimiento de riesgos en aspectos sociales y medioambientales, potencialidades o cuestiones que antes pasaban desapercibidas, permitiendo a la empresa posicionarse, presentar los aspectos diferenciales y las acciones que un informe tradicional no permitía mostrar, o hacer comparaciones con otras organizaciones o de la misma organización a lo largo del tiempo.

La necesidad de transparencia de la organización exige disponer de un estándar ampliamente aceptado para la elaboración de las memorias. En un principio cada empresa elaboraba los informes a su manera decidiendo qué datos incluir y cuáles omitir, dificultando la comparación de las informaciones. Para paliar este problema surgieron las directrices internacionales GRI (Global Reporting Initiative) para la elaboración de "memorias de sostenibilidad" con una cierta uniformidad de criterios, incluyendo una serie de indicadores, que faciliten la transparencia y comparabilidad. La aplicación de los criterios del GRI para la elaboración de las memorias está cada vez más extendida a nivel mundial y aporta un plus de credibilidad a la información que se presenta.

El Programa de Naciones Unidas para el Medio Ambiente (PNUMA/UNEP) y la organización estadounidense CERES impulsaron el proyecto de la Global Reporting Initiative a fin de proporcionar a las empresas una guía que les permitiera comunicar su contribución al desarrollo sostenible, teniendo en cuenta las demandas de sus grupos de interés, estableciendo estándares de informes homogéneos y comparables ${ }^{24}$. La elaboración de una memoria de sostenibilidad comprende la medición, divulgación y rendición de cuentas frente a grupos de interés internos y externos en relación con el desempeño de la organización con respecto al objetivo del desarrollo sostenible. La Guía de 2006 hace la siguiente propuesta de contenido del informe de sostenibilidad $^{25}$ :

\section{Estrategia y análisis, que debe incluir una declaración del máximo responsable} sobre la relevancia de la sostenibilidad para la organización y su estrategia; y una descripción de los principales impactos, riesgos y oportunidades: se pretende que la organización explique la prioridad que concede a los riesgos y oportunidades que implican los impactos de sus actividades y los impactos de las "tendencias de sostenibilidad" sobre la organización.

2. Perfil de la organización, que es la descripción básica de la organización: nombre; principales marcas, productos o servicios; estructura; localización de la sede principal; países en los que tiene actividades; naturaleza de la propiedad y forma

24 La GRI fue creada inicialmente en 1998 como un proyecto de CERES (Coalition for Environmentally Responsible Economies). CERES creó un Comité Directivo de la GRI y funcionó como secretaría de la iniciativa hasta el año 2001. PNUMA apoyó la iniciativa GRI, la cual publicó, en 2000, la primera versión de sus líneas directrices para la elaboración de informes de sostenibilidad. En 2001, la GRI se convirtió en una organización totalmente independiente. En 2002 dio a conocer la segunda versión de las directrices de presentación de informes de sostenibilidad. La tercera versión fue publicada en 2006.

25 Véase GRI “Guía para la elaboración de Memorias de Sostenibilidad”, versión 3.0, Global Reporting Initiative, Amsterdam, 2006; como ejemplo puede verse el "Informe de Responsabilidad Corporativa 2007" de NH Hoteles. 
jurídica; mercados; dimensiones (número de asalariados, ventas y costos por país, capitalización total, principales accionistas, y cambios significativos durante el período cubierto por el informe respecto al tamaño, estructura o propiedad de la empresa u organización).

3. Parámetros de la memoria, integrados por su perfil, el alcance y la cobertura, el índice de contenidos y la política con respecto a la verificación:

- el perfil de la memoria incluye el período que abarca el informe (si la empresa presenta informes anuales o utiliza otro período y la fecha del informe más reciente, si lo hubiere. La mayoría de las memorias abarcan un año civil y se publican el año siguiente);

- el alcance y la cobertura se refieren a lo que abarca el informe. Describen cómo se determinó la relevancia y cuáles serán los temas así como los grupos de interés que se espera utilicen el informe. El alcance se presenta en forma de una descripción del proceso mediante el cual se define el contenido del informe. La cobertura se refiere a la serie de entidades que la empresa incluye en su informe. El enfoque de la Guía G3 en relación con la cobertura es considerarla como la serie de entidades (filiales, empresas conjuntas, subcontratistas) sobre las que la empresa informante ejerce control o influencia. La cobertura debe incluir la cuestión de la subcontratación, que a menudo tiene repercusiones negativas sobre los trabajadores y las comunidades. Con frecuencia, las empresas subcontratan para reducir costes o evitar las obligaciones que la legislación laboral les impone. Si, por algún motivo, el alcance no es tan amplio como debiera o la cobertura es inferior a lo debido, es preciso explicar dichas limitaciones;

- un índice de contenido de los diversos contenidos básicos de la memoria;

- por último, en los parámetros de la memoria deben describirse la política y las prácticas actuales en relación con la verificación.

4. Gobierno, compromisos y participación de los grupos de interés:

- la estructura de gobierno de una organización es el sistema mediante el cual toma sus decisiones y la forma en que quienes toman las decisiones asumen su responsabilidad y rinden cuentas. Las organizaciones también deben informar sobre los mecanismos que permiten a sus empleados hacer recomendaciones al máximo órgano de gobierno y los procesos de información y consulta de los trabajadores, tales como los comités de empresa o su representación en el máximo órgano de gobierno;

- los compromisos con iniciativas externas se refieren a las organizaciones, actividades y proyectos que se relacionen con el desempeño ambiental, económico o social en los que la empresa participa. Estos compromisos pueden incluir asociaciones con ONGs u organismos gubernamentales y la pertenencia o apoyo a organizaciones multipartitas, p. ej. sectoriales, y nacionales/internacionales;

- la participación de los grupos de interés: la organización debe identificar a sus grupos de interés y describir cómo ha dado respuesta a sus expectativas e intereses razonables. También debe informar sobre el diálogo que mantiene con las 
partes interesadas. Aunque su participación no significa que intervengan en la toma de decisiones, la empresa debe comprometerse con la intención de informarles de sus decisiones. Para que la memoria sea verificable, debe documentar el proceso de participación de los grupos de interés, señalar cuáles han participado, cómo y cuándo lo hicieron y cómo ha afectado esa participación al contenido de la memoria y a las actividades de sostenibilidad desarrolladas por la organización.

5. Indicadores de actuación o desempeño: para evaluar el progreso en las políticas de RSE es necesario contar con un conjunto de indicadores que permitan disponer de información comparable respecto a la actuación económica, ambiental y social de la organización. Los indicadores pueden ser la parte más importante de la memoria, ya que a través de ellos se pueden hacer comparaciones. Para medir el desempeño de las empresa sobre diversos aspectos, la Guía utiliza seis "categorías de indicadores": económicos, medioambientales, prácticas laborales, derechos humanos, sociedad y responsabilidad sobre productos. Los indicadores, en total 79, están clasificados en "principales" o "adicionales". Las organizaciones deben presentar información sobre los principales a menos que se consideren no relevantes de conformidad con los principios de elaboración de memorias de GRI. Los adicionales abordan temas que pueden ser relevantes para algunas empresas y para otras no. Quizá el interés de algunos de los indicadores exigidos resulte un tanto discutible para el caso de las empresas turísticas ${ }^{26}$.

26 Otros elementos son los "suplementos sectoriales" que abordan cuestiones consideradas específicas a cada uno de los sectores industriales. Existen varios suplementos sectoriales: el del vestido y calzado, empresas eléctricas, servicios financieros, organismos públicos, automotriz, logística y transporte, telecomunicaciones, minería, organizaciones sin fines de lucro y operadores turísticos. GRI ha elaborado, en cooperación con la Iniciativa de Tour Operadores (TOI), directrices de informes de sostenibilidad en el sector de tour operadores, que comprenden indicadores marco de GRI y otros adicionales, especificos para el sector turístico. Pero este sistema de elaboración de informes acerca de la sostenibilidad en el sector del turismo no se aplica en la vida real del trabajo de las empresas del turismo (puede consultarse en internet "Tour Operators 'Sector Supplement. Sustainability Reporting Guidelines. For use with the GRI 2002”, GRI, Amsterdam, 2002). 
Cuadro 3. Indicadores de actuación según GRI 2006.

\begin{tabular}{|c|c|c|}
\hline Categorías de indicadores & Aspectos & Algunos ejemplos \\
\hline Económicos (9) & $\begin{array}{l}\text { Desempeño económico } \\
\text { Presencia en el mercado } \\
\text { Impactos económicos indirectos }\end{array}$ & $\begin{array}{l}\text { Rango de las ratios correspondiente al } \\
\text { salario inicial estándar en comparación } \\
\text { con el salario mínimo local en lugares } \\
\text { donde se desarrollan operaciones signifi- } \\
\text { cativas } \\
\text { Política, prácticas y proporción de gasto } \\
\text { correspondiente a proveedores locales en } \\
\text { lugares donde se desarrollen operaciones } \\
\text { significativas } \\
\text { Procedimientos para la contratación local } \\
\text { y proporción de altos directivos proce- } \\
\text { dentes de la comunidad local en lugares } \\
\text { donde se desarrollen operaciones signifi- } \\
\text { cativas }\end{array}$ \\
\hline Medioambientales (30) & $\begin{array}{l}\text { Materiales } \\
\text { Energía } \\
\text { Agua } \\
\text { Biodiversidad } \\
\text { Emisiones, vertidos y residuos } \\
\text { Productos y servicios } \\
\text { Cumplimiento normativo } \\
\text { Transporte } \\
\text { General }\end{array}$ & $\begin{array}{l}\text { Consumo directo de energía desglosada } \\
\text { por fuentes primarias } \\
\text { Porcentaje y volumen total de agua reci- } \\
\text { clada y reutilizada } \\
\text { Emisiones de sustancias destructoras de } \\
\text { la capa de ozono, en peso } \\
\text { Peso total de residuos gestionados, según } \\
\text { tipo y método de tratamiento }\end{array}$ \\
\hline $\begin{array}{l}\text { Prácticas laborales y } \\
\text { ética en el trabajo (14) }\end{array}$ & $\begin{array}{l}\text { Empleo } \\
\text { Relaciones empre- } \\
\text { sa/trabajadores } \\
\text { Salud y seguridad en el trabajo } \\
\text { Formación y educación } \\
\text { Diversidad e igualdad de opor- } \\
\text { tunidades }\end{array}$ & $\begin{array}{l}\text { Desglose del colectivo de trabajadores } \\
\text { por tipo de empleo, por contrato y por } \\
\text { región } \\
\mathrm{N}^{\mathrm{o}} \text { total de empleados y rotación media } \\
\text { de empleados, desglosados por grupos de } \\
\text { edad, sexo y región } \\
\text { Porcentaje de empleados cubiertos por } \\
\text { un acuerdo colectivo } \\
\text { Tasas de absentismo, enfermedades pro- } \\
\text { fesionales, días perdidos y } \mathrm{n}^{\circ} \text { de víctimas } \\
\text { mortales relacionadas con el trabajo por } \\
\text { región } \\
\text { Relación entre salario base de los hom- } \\
\text { bres con respecto al de las mujeres, des- } \\
\text { glosado por categoría profesional }\end{array}$ \\
\hline
\end{tabular}




\section{Categorías de indicadores}

Sociedad (8)

Responsabilidad sobre productos (9)
Aspectos

Algunos ejemplos
Prácticas de inversión y abastecimiento

No discriminación

Libertad de asociación y convenios colectivos

Explotación infantil

Trabajos forzados

Prácticas de seguridad

Derechos de indígenas
Porcentaje de los principales distribuidores y contratistas que han sido objeto de análisis en materia de derechos humanos y medidas adoptadas como consecuencia Actividades de la compañía en las que el derecho a libertad de asociación y de acogerse a convenios colectivos puedan correr importantes riesgos, y medidas adoptadas para respaldar estos derechos $\mathrm{N}^{\mathrm{o}}$ total de incidentes de discriminación y medidas adoptadas

Naturaleza, alcance y efectividad de programas y prácticas para evaluar y gestionar los impactos de las operaciones en las comunidades, incluyendo entrada, operación y salida

Posición en las políticas públicas y participación en el desarrollo de las mismas y de las actividades de "lobbying"

$\mathrm{N}^{\mathrm{o}}$ total de acciones por causas relacionadas con prácticas monopolísticas

$\mathrm{N}^{\mathrm{o}}$ total de incidentes fruto del incumplimiento de las regulaciones relativas a las comunicaciones de marketing

$\mathrm{N}^{\mathrm{o}}$ total de reclamaciones fundamentadas en relación con el respeto de la privacidad y la fuga de datos personales de clientes

Coste de aquellas multas significativas fruto del incumplimiento de la normativa en relación con el suministro y el uso de productos y servicios de la organización

Fuente: Elaboración propia a partir de Guía GRI 2006.

Hay tres niveles de calificación: C, B y A, que son determinados por una autoevaluación de la memoria, revisados por una tercera parte o revisados según los criterios de GRI. La elección es voluntaria y las organizaciones que presentan memorias deben decidir cuál es la que mejor cubre sus necesidades. Los niveles $\mathrm{C}+, \mathrm{B}+\mathrm{y} \mathrm{A}+\mathrm{se}$ otorgan cuando existe una verificación externa. El nivel A+ constituye el mayor grado de utilización de las recomendaciones de Global Reporting Initiative, muestra transparencia pero no es un juicio sobre la sostenibilidad de la empresa que presenta la memo- 
ria $^{27}$. En principio, se plantea que la verificación externa sea comparable a la de un auditor financiero a la hora de elaborar los estados de cuentas financieros anuales, pero en la práctica no es así. Las empresas verificadoras puede que no hayan realizado ninguna comprobación externa respecto a lo que afirma la memoria, sólo analizan dicha memoria, la documentación y el proceso utilizado para elaborarla. A este respecto, algunos señalan la necesidad de evitar que las certificaciones y auditorías de conviertan en un simple negocio más para algunas empresas dedicadas a esta labor.

Muchas memorias no resultan creíbles, hacer memorias en las que sólo se destacan los aspectos importantes y se ocultan los negativos acaba devaluando el valor de las mismas. Una gran mayoría de los españoles creen que los informes de RSE no tratan los asuntos importantes, que omiten la información relevante, o que parecen tener un propósito más bien cosmético (Fundación Alternativas, 2008). Las memorias deben proporcionar una imagen equilibrada y razonable del desempeño en materia de sostenibilidad, e incluir tanto las contribuciones positivas como las negativas.

\section{CONCLUSIÓN}

Cada empresa debe adoptar un sistema propio para integrar la responsabilidad social en su vida cotidiana. Los sistemas estándar establecidos pueden servir de base y orientación, por ejemplo se puede desarrollar un sistema de gestión ambiental utilizando las normas certificables ISO 14001 o EMAS, para agregar algunos criterios sociales, que tienen relevancia para la industria del turismo, como podría ser la norma SA8000 de auditoría social ${ }^{28}$, certificada por un auditor externo, lo que dará a los turistas una seguridad de que son clientes de una empresa verdaderamente responsable en los ámbitos medioambiental y social.

En muchos países existe una gran brecha entre los requerimientos impuestos por las normas fundamentales de vigencia internacional y la realidad. Muchas grandes empresas informan suficientemente sobre sus políticas e impactos laborales en sus países de origen, pero no lo hacen sobre sus actuaciones en otros países, en donde más fácilmente son vulnerados los derechos laborales. Para garantizar el cumplimiento de unos estándares sociales en países donde no se cumplen unos mínimos, es importante que se realice un control externo por parte de una institución independiente de la empresa en cuestión, que coopere con actores locales como sindicatos y ONGs. El cumplimiento de la RSE puede contribuir a la mejora de las condiciones de vida y de trabajo en esos países y regiones donde no se respetan los derechos humanos o laborales básicos.

27 Datos en www.globalreporting.org, base de datos en GRIreportsdatabase. E1 76\% de los informes publicados en 2007 en España y registrados por GRI ha seguido la guía G3. El 64\% de los informes ha sido calificado como $\mathrm{A}+$.

28 Aparte de otros sistemas de gestión de calidad total (Total Quality Management Systeme: TQM, EFQM, etc.) y sistemas especiales que se aplican al sector del turismo como, por ejemplo, Swiss Tourism Quality Label, Green Globe Standard, Costa Rica Tourism Label, Australian National Ecotourism Accreditation Programme, etc. 
Hasta ahora han sido las grandes empresas turísticas las que más han hecho públicas sus iniciativas en responsabilidad social. Para ellas es más importante la imagen pública y están más expuestas a las críticas de las ONGs o de los medios de comunicación. Son ellas las que se adhieren al Pacto Mundial o las que redactan informes siguiendo el modelo de GRI. En cambio, se suele tener una imagen de que las pequeñas y medianas empresas van mucho más rezagadas en adoptar prácticas responsables, y que es en ellas en donde más esfuerzos es necesario hacer. De modo que se pide a las grandes empresas que demanden comportamientos responsables a sus proveedores, a esas pequeñas y medianas empresas que les sirven de suministradoras (en ello pueden tener un papel destacado los responsables de compras de las grandes empresas). Y hay que tener en cuenta que la mayoría de las empresas son pequeñas y medianas, por lo que la verdadera responsabilidad social se alcanzará cuando éstas (en Europa un 70\% de la capacidad total de alojamiento turístico corresponde a compañías de pequeño y mediano tamaño, algunas estimaciones sobre el mundo en desarrollo arrojan una cifra de hasta un $85 \%$ ) la asuman como una oportunidad de mejora.

De todas formas, la realidad no siempre es como parece, y de hecho muchas de las grandes empresas que, aparentemente, son punteras en asumir la responsabilidad social, realmente no llevan a la práctica mucho de lo que pregonan. Por ejemplo, sólo una pequeña parte de las grandes empresas españolas que figuran en el índice IBEX 35 obtienen hoy en día un aprobado en RSE, de manera que los progresos en la cultura de la responsabilidad en el grupo más selecto de las mayores empresas españolas es excesivamente lento (García Perdiguero y García Reche, 2009). En cambio, muchas pequeñas y medianas empresas, que no figuran en las grandes iniciativas, sí están asumiendo muchos de los principios de responsabilidad social. Pensemos en casas de turismo rural o iniciativas relacionadas con el turismo justo o el turismo comunitario en zonas del Centro y del Sur de América, o en lugares como Sudáfrica. Muchos de esos ejemplos no se certifican, no exhiben etiquetas, porque no les hace falta, porque todo el mundo sabe que desarrollan una determinada forma de turismo, más o menos sostenible, pero sin impacto negativo en cuestiones medioambientales o sociales.

Un problema es que muchas empresas confunden la responsabilidad social con la acción social o el marketing con causa. La diferencia entre la RSE y la utilización de las acciones sociales para publicitar la imagen de empresa está en la respuesta que comporta a los propios intereses empresariales y el necesario equilibrio con todos los grupos de interés de la organización. Si una persona u organización tiene claros sus valores éticos y su espíritu de servicio a la sociedad, su enriquecimiento material e intelectual le permite ofrecer más y mejor al medio del que recibe.

Otro problema es el de la verificación, algunas empresas hacen una memoria que está verificada y comprobada, mientras en otras el auditor sólo certifica que la empresa ha elaborado la memoria, pero sin verificar los datos que en ella se presentan. Aunque la RSE sea una opción voluntaria para las empresas, parece necesario que exista alguna forma (a través de organismos internacionales o de los gobiernos) de controlar que cumplen unos requisitos, que resulten más creíbles de lo que lo son hoy, que se pase de las palabras a los hechos. 


\section{BIBLIOGRAFÍA}

ACSUD Las Segovias (2003): “Criterios para un turismo justo. Una primera aproximación", Valencia.

Ashley, C.; Goodwin, H. et al.(2006): "Making Tourism Count for the Local Economy in the Caribbean: Guidelines for Good Practice”, Pro-Poor Tourism Partnership y Caribbean Tourism Organisation.

Ayuso Siart, S. (2003) "Gestión sostenible en la industria turística. Retórica y práctica en el sector hotelero español", tesis doctoral, Universitat Autónoma de Barcelona.

Bestratén, M. y Pujol, L. (2003): "NTP 643: Responsabilidad social de las empresas (I): conceptos generales" y "NTP 644: Responsabilidad social de las empresas (II): tipos de responsabilidades y plan de actuación" Instituto Nacional de Seguridad e Higiene en el Trabajo", Ministerio de Trabajo y Asuntos Sociales, Madrid.

Caballero, I. y Balaguer, A. I. (2004): "NTP 647: Responsabilidad social de las empresas Modelo SAI 8000 (Social Accountability)", Instituto Nacional de Seguridad e Higiene en el Trabajo", Ministerio de Trabajo y Asuntos Sociales, Madrid.

Cañada, Ernest (2008): "Organización sindical frente a las cadenas hoteleras españolas en América Latina”, ATR/Alba Sud, 01-10-2008.

Confederación de Consumidores y Usuarios (CECU) (2008): "La opinión y valoración de los consumidores sobre la Responsabilidad Social de la Empresa en España. Edición 3 ${ }^{\text {', }}$, en http://www.cecu.es/GuiaRSE3.pdf.

Comisión Europea (2001): "Libro Verde: Fomentar un marco europeo para la responsabilidad social de las empresas".

Comisión de las Comunidades Europeas (2003): "Orientaciones básicas para la sostenibilidad del turismo europeo: Comunicación de la Comisión al Consejo, al Parlamento Europeo, al Comité Económico y Social y al Comité de las Regiones", Bruselas, 21.12.2003 COM (2003) 716 final.

Exceltur (2003): "Acción Social en la Empresa Turística”, Alianza para la Excelencia Turística (Exceltur), Madrid.

Fundación Alternativas (2008): "La confianza social en las empresas españolas. Informe 2008. La Responsabilidad Social Corporativa en España", Fundación Alternativas, Madrid.

Fuentes, F., Veroz, R. y Saco, F. (2006): "La responsabilidad social corporativa en la gestión de los recursos humanos", en L. Vargas, op. cit.

García Perdiguero, T. y García Reche, A. (2009): “Cultura, políticas y prácticas de responsabilidad de las empresas del IBEX 35. Estudio 2008", Grup d'Investigacio sobre la Responsabilitat Social de les Empreses. Universitat de ValènciaObservatorio de la Responsabilidad Social de la Empresa.

GRI (2002): “Tour Operators'Sector Supplement. Sustainability Reporting Guidelines. For use with the GRI 2002", GRI, Amsterdam, en https://www.sdn.sap.com/ $\mathrm{irj} / \mathrm{scn} / \mathrm{go} / \mathrm{portal} / \mathrm{prtroot} / \mathrm{docs} / \mathrm{library} / \mathrm{uuid} / 60249975-\mathrm{e} 07 \mathrm{f}-2 \mathrm{a} 10-\mathrm{e} 384-\mathrm{a} 815290160 \mathrm{~d} 6$ 
GRI (2006): “Guía para la elaboración de Memorias de Sostenibilidad”, versión 3.0, Global Reporting Initiative, Amsterdam.

Guillén Gestoso, C. y Contreras Chamorro, R. (dirs.) (2008): “Discapacitados y empresas: un análisis de la productividad. El coste de oportunidad desconocido", Fundación Mapfre, en http://www.mapfre.com/ccm/content/documentos/fundacion/accionsocial/Discapacitados-y-empresa.pdf

Jiménez Fernández, Juan C. (2007): “La Responsabilidad Social de la Empresa, cómo entenderla, cómo afrontarla. Una perspectiva sindical”, Altabán Ediciones, Albacete.

KATE, EED-Tourism Watch Bonn- y ACSUD Valencia (2006): “RSC. Empresas turísticas y su responsabilidad global".

López Gómez, Ma Dolores (2007): “Turismo sin desarrollo”, Intermón-Oxfam.

NH Hoteles (2007): "Informe de Responsabilidad Corporativa 2007 de NH Hoteles".

Observatorio de Responsabilidad Social Corporativa (2007): "La Responsabilidad Social Corporativa en las memorias anuales de las empresas del IBEX 35. Análisis del ejercicio 2007" en http://www.observatoriorsc.org/images/documentos/publicaciones/ informes_estudios/obrsc_informe07_ibex_completo.pdf

OMT (2003) “Turismo y atenuación de la pobreza”, Organización Mundial del Turismo, Madrid.

Palomo Pérez, S. (2006a): "El turismo justo y la creación de sistemas de producción de servicios turísticos responsables”, Estudios Turísticos, 168: 7-46.

Palomo Pérez, S. (2006b): "I Encuentro Internacional de Turismo Justo. Documento estratégico. Versión definitiva", 1-2 junio 2006. Palacio de Congresos y Exposiciones de la costa del Sol (Torremolinos), Diputación de Málaga, en http://www.iemed.org/documents/turismojustopalomo.pdf

Vargas Escudero, L. (2006): “Mitos y realidades de la Responsabilidad Social Corporativa en España. Un enfoque multidisciplinar", Thomson-Civitas, Navarra.

Varios Autores (2005): “Diálogo sobre Responsabilidad Social Corporativa en el Sector del Turismo”, KATE Stuttgart.

Veloz Gutiérrez, E. C., coor. (2008): “ISO 26000 y derechos laborales. Reflexiones y perspectivas desde las organizaciones sindicales y ciudadanas", Fundación Friedrich Ebert-Representación en México y Red Puentes-México, México. 